\title{
Adrenergic receptor blockade-induced regression of pressure- overload cardiac hypertrophy is associated with inhibition of the calcineurin/NFAT3/GATA4 pathway
}

\author{
DACHUN YANG*, SHUANGTAO MA*, YAN TAN, DE LI, BING TANG, JINSONG CHEN, \\ XIAOHUA SU, GANG LI, XIN ZHANG and YONGJIAN YANG
}

Department of Cardiology, General Hospital of PLA Chengdu Military Area Command, Chengdu, Sichuan 610083, P.R. China

Received December 31, 2009; Accepted March 9, 2010

DOI: $10.3892 / \mathrm{mmr} 00000287$

\begin{abstract}
Calcineurin and its downstream effectors nuclear factor of activated T-cells 3 (NFAT3) and zinc finger-containing transcription factor (GATA4) have been implicated in the development of cardiac hypertrophy. The aims of the present study were to investigate alterations in the calcineurin/NFAT3/GATA4 pathway in pressure-overload hypertrophy, and to determine whether adrenergic receptor blockade affects this signaling pathway. In aorta-banded rats compared with sham-operated rats, a significant increase in the phosphorylation levels of calcineurin and GATA4 was observed (both $\mathrm{p}<0.05$ ), while the NFAT3 phosphorylation level was markedly decreased $(\mathrm{p}<0.05)$. Oral administration of either the non-selective $\beta$ blocker/ $\alpha-1$ blocker carvedilol or the selective $\beta-1$ blocker metoprolol, but not the selective $\alpha-1$ blocker terazosin, significantly suppressed the activated calcineurin/NFAT3/GATA4 pathway (all p<0.05) in addition to inducing a regression of cardiac hypertrophy. Pressure overload-induced up-regulation of c-myc was markedly attenuated by treatment with either carvedilol or metoprolol (both $\mathrm{p}<0.05$ ). The present findings may expand our understanding of the correlation between sympathetic activity and the calcineurin/NFAT3/GATA4 pathway, and highlight these signal transducers as effective targets in the management of pressure overload-induced cardiac hypertrophy.
\end{abstract}

\section{Introduction}

Cardiac hypertrophy is a leading cause of the development of congestive heart failure and sudden death in humans (1).

Correspondence to: Dr Yongjian Yang, Department of Cardiology, General Hospital of PLA Chengdu Military Area Command, Tianhui, Jinniu, Chengdu, Sichuan 610083, P.R. China

E-mail: yongjiany@yahoo.cn

*Contributed equally

Key words: calcineurin, nuclear factor of activated T-cells 3, zinc finger-containing transcription factor, carvedilol, metoprolol
A clear understanding of the cellular and molecular mechanisms underlying cardiac hypertrophy is critical in the effort to address heart failure. Over the past decade, several intracellular signaling pathways have been implicated in the regulation of cardiac hypertrophy (2). It is generally accepted that calcineurin, a $\mathrm{Ca}^{2+} /$ calmodulin-dependent protein phosphatase, is activated in the hypertrophic and failing heart (3-5). Activated calcineurin dephosphorylates its downstream transcriptional effector nuclear factor of activated T-cells 3 (NFAT3) (6). Subsequently, the dephosphorylated NFAT3 enters the nucleus where it interacts with cardiac-restricted zinc finger-containing transcription factor (GATA4) and causes the transcriptional activation of hypertrophic fetal genes (such as c-myc), leading to cardiac hypertrophy (6). It has been reported that the calcineurin inhibitors cyclosporine A and FK506 prevent the development of pressure-overload hypertrophy in several animal models (7-11). The risk of long-term adverse effects of immunosuppressants should be carefully assessed, as cyclosporine A may directly induce cancer progression (12). Thus, it is necessary to develop a novel strategy for the suppression of calcineurin activity.

Adrenergic receptors play a pivotal role in the development of cardiac hypertrophy in response to pressure overload (13). The activation of adrenergic receptors, a hallmark of pressureoverload cardiac hypertrophy, influences several cellular processes by increasing intracellular $\mathrm{Ca}^{2+}$ levels (14). As previously reported, a sustained $\mathrm{Ca}^{2+}$ elevation is required for the activation of calcineurin (15). This strongly suggests that adrenergic receptor blockade affects the calcineurin/NFAT3/ GATA4 pathway.

In this context, the present study was designed to investigate alterations in the calcineurin/NFAT3/GATA4 pathway in pressure-overload hypertrophy, and to determine whether adrenergic receptor blockade is capable of normalizing this signaling pathway, besides inducing a regression of pressureoverload cardiac hypertrophy.

\section{Materials and methods}

Animal care. Male Wistar rats aged 8 weeks were obtained from a local animal center. The rats were fed standard chow and tap water ad libitum and kept in a controlled environment 
Table I. Hemodynamic and ventricular remodeling parameters of rats.

\begin{tabular}{lccccr}
\hline Groups & Sham & Vehicle & Carvedilol & Metoprolol & Terazosin \\
\hline LVHI (mg/g) & $2.33 \pm 0.18$ & $3.47 \pm 0.24^{\mathrm{a}}$ & $2.65 \pm 0.19^{\mathrm{b}}$ & $2.98 \pm 0.25^{\mathrm{b}, \mathrm{c}}$ & $3.36 \pm 0.31$ \\
RVHI (mg/g) & $0.68 \pm 0.06$ & $0.66 \pm 0.05$ & $0.66 \pm 0.07$ & $0.66 \pm 0.04$ & $0.65 \pm 0.05$ \\
HR (BPM) & $389 \pm 10.0$ & $435 \pm 11.0^{\mathrm{a}}$ & $315 \pm 13.0^{\mathrm{b}}$ & $379 \pm 20.0^{\mathrm{b}, \mathrm{c}}$ & $430 \pm 22.0$ \\
MAP (mmHg) & $106 \pm 10.1$ & $224.2 \pm 11.6^{\mathrm{a}}$ & $141 \pm 13.0^{\mathrm{b}}$ & $176 \pm 12.6^{\mathrm{b}, \mathrm{c}}$ & $131.0 \pm 11.3^{\mathrm{b}}$ \\
LVEDP (mmHg) & $4.2 \pm 0.7$ & $14.0 \pm 1.2^{\mathrm{a}}$ & $8.3 \pm 0.8^{\mathrm{b}}$ & $11.1 \pm 1.0^{\mathrm{b}, \mathrm{c}}$ & $12.0 \pm 0.1$ \\
\hline
\end{tabular}

Data are the means \pm SD of 10 rats per group. LVHI, left ventricular hypertrophy index; RVHI, right ventricular hypertrophy index; HR, heart rate; MAP, mean arterial blood pressure; LVEDP, left ventricular end-diastolic pressure; ${ }^{a} \mathrm{p}<0.05 \mathrm{vs}$. sham; ${ }^{\mathrm{b}} \mathrm{p}<0.05 \mathrm{vs}$. vehicle; ${ }^{\mathrm{c} p}<0.05 \mathrm{vs}$. carvedilol.

under a 12-h dark/light cycle. The handling of animals and all experimental procedures were approved by the Institutional Animal Care and Use Committee of the General Hospital of PLA Chengdu Military Area Command.

Aortic banding. Suprarenal aortic banding was produced as previously described (16). Briefly, under ketamine anesthesia (100 mg/kg, i.p.), a laparotomy was performed to expose the descending aorta near the origin of the left renal artery. The abdominal aorta proximal to the left renal artery was constricted with a 3-0 silk suture ligature tied against a 22-gauge wire. The wire was later removed, leaving the vessel constricted to $60-70 \%$ of its original diameter. Sham-operated rats underwent the identical procedure, but the isolated aorta was not constricted. The abdomen was closed after antibiotic prophylaxis using penicillin (10,000 units). Only rats that survived $24 \mathrm{~h}$ post-operatively were used in the following experiments.

After surgery, animals were randomly assigned to one of five separate groups: i) sham-operated rats treated with vehicle $(n=10)$, ii) aortic banded rats treated with vehicle $(n=10)$, iii) aortic banded rats treated with carvedilol $(30 \mathrm{mg} / \mathrm{kg} / \mathrm{d}$, gavage, $\mathrm{n}=10)$, iv) aortic banded rats treated with metoprolol $(50 \mathrm{mg} /$ $\mathrm{kg} / \mathrm{d}$, gavage, $\mathrm{n}=10$ ), and v) aortic banded rats treated with terazosin ( $2 \mathrm{mg} / \mathrm{kg} / \mathrm{d}$, gavage, $\mathrm{n}=10)$. The tail-cuff systolic arterial blood pressure and heart rate were measured in conscious rats at baseline and once a week after surgery.

Hemodynamic measurement. After 2 weeks of treatment, the rats were anesthetized with urethane $(1.2 \mathrm{~g} / \mathrm{kg}$, i.p.). The right carotid artery was cannulated with a polyethylene tube and forwarded to the aortic arch. The tube was connected to a pressure transducer. The heart rate (HR), left ventricular end-diastolic pressure (LVEDP) and mean arterial blood pressure (MAP) were recorded in synchronism with the RM-6000 polygraph system (Nihon Kohaden, Japan).

Heart weight. Rats were sacrificed after hemodynamic measurement, then the hearts were excised for the measurement of left and right ventricle weight. The left ventricular hypertrophy index (LVHI) and the right ventricular hypertrophy index (RVHI) were calculated. A thin transverse slice of left ventricular free wall was removed and fixed in $10 \%$ buffered formalin and embedded in paraffin. The remaining left ventricular tissue was dissected and frozen at $-80^{\circ} \mathrm{C}$ for Western blotting.

Western blot analysis. Western blotting was performed as previously reported by our group (17). Protein lysates were obtained by homogenizing ventricular tissues with lysis buffer. Protein concentration was determined with a commercial reagent (Bio-Rad Laboratories, USA). Equal amounts of protein from heart extracts were separated by SDS-PAGE (12\%). The samples were then electroblotted onto a nitrocellulose membrane (Boehringer Mannheim Corporation, USA) and probed with antibodies against total and phospho-calcineurin/ NFAT3/GATA4 and c-myc (1:500 dilution, polyclonal) supplied by $\mathrm{Dr} \mathrm{Mu}$ ) University of California-San Francisco, CA, USA). After washing, the membrane was incubated with a horseradish peroxidase-conjugated secondary antibody (1:1,000 dilution; Santa Cruz Biotechnology, USA) and bound antibodies were visualized using a colored reaction. The relative band densities were quantified by densitometry using the Multi-Analyst software package (Bio-Rad Laboratories). Equal protein loading was confirmed by measuring $\beta$-actin expression.

Pathohistological analysis. Histological analysis of the heart tissue was performed according to previously described methods (16). Ventricular sections were stained with H\&E for routine histological examination.

Statistical analysis. Data are presented as the means \pm SEM. Comparisons between groups were determined by one-way ANOVA with the Student's [post hoc] t-test (SPSS Inc., USA). Results were considered significant at $\mathrm{p}<0.05$.

\section{Results}

Hemodynamic and cardiac hypertrophic parameters. After 2 weeks of pressure overload, the LVHI, HR, MAP and LVEDP were significantly increased in aorta-constricted rats compared to the sham-operated group (all p<0.05) (Table I). Treatment with the non-selective $\beta$ blocker/ $\alpha-1$ blocker carvedilol or the selective $\beta-1$ blocker metoprolol successfully suppressed the elevation of the LVHI, HR, MAP and LVEDP caused by pressure overload (all $\mathrm{p}<0.05)$ (Table I). Carvedilol was found to be much more effective than metoprolol in this 


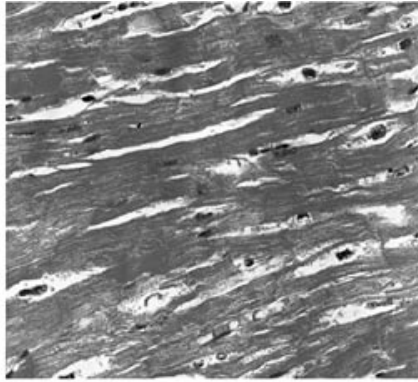

Sham-operated

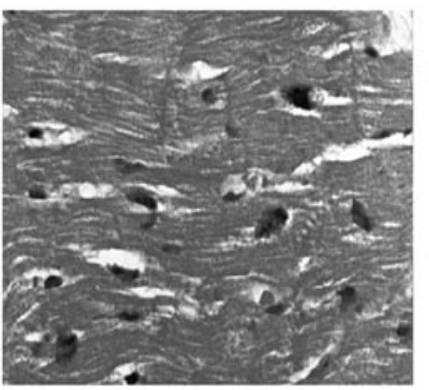

Carvedilol-treated

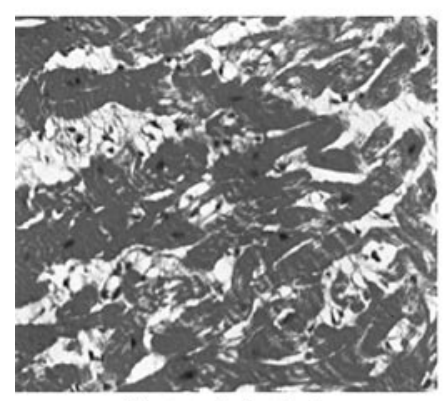

Terazosin-treated

Figure 1. Representative histological sections showing pathological changes in the ventricles of sham-operated rats treated with vehicle and aorta-banded rats treated with vehicle, carvedilol, metoprolol or terazosin. Sections were stained with H\&E. Magnification x200.

respect (all $\mathrm{p}<0.05)$ (Table I). Additionally, treatment with the selective $\alpha-1$ blocker terazosin significantly attenuated the aortic banding-induced elevation of MAP $(\mathrm{p}<0.05)$, but failed to affect cardiac hypertrophy parameters, including LVHI and LVEDP (Table I).

Pathological analysis of ventricular hypertrophy. Histological sections of ventricles from sham-operated rats displayed normal morphology and well-arranged sarcomeres (Fig. 1). As expected, ventricular sections from vehicle-treated rats with aorta banding exhibited hypertrophic cardiomyocytes, caliber variations and disturbed tissue architecture (Fig. 1). Significantly, aorta banding-induced ventricular hypertrophy was successfully prevented by treatment with carvedilol, and was partially relieved by metoprolol (Fig. 1). However, treatment with terazosin failed to ameliorate ventricular hypertrophy caused by pressure overload (Fig. 1).

Phosphorylation and expression of the calcineurin/NFAT3/ GATA4 pathway. As expected, the aortic banding of the rats induced a significant increase in the phosphorylation levels of calcineurin and GATA4 (both $\mathrm{p}<0.05$ ), but a marked decrease
A

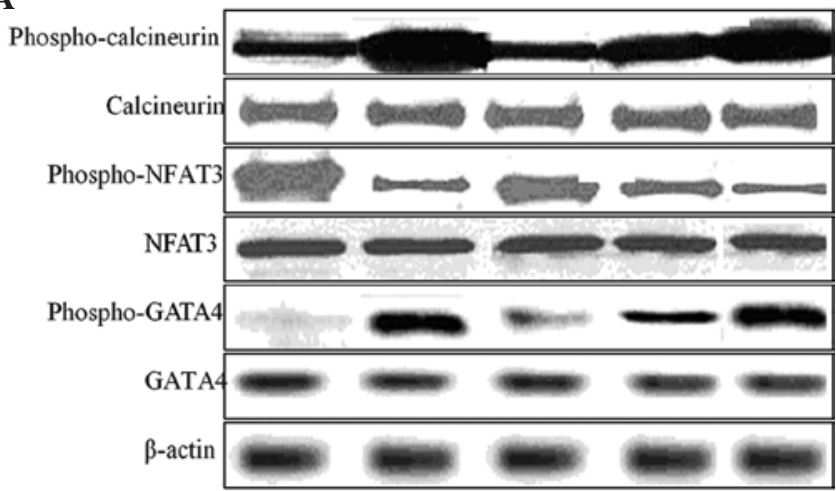

B

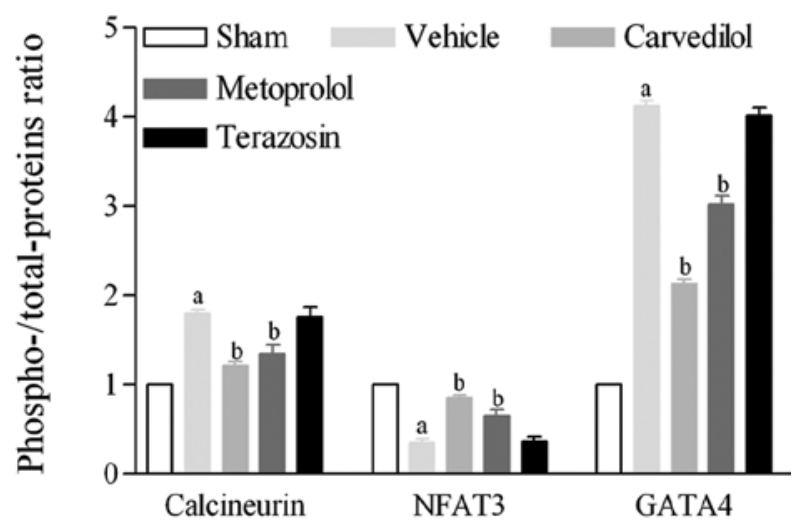

Figure 2. Protein expression and phosphorylation status of the calcineurin/ NFAT3/GATA4 pathway. Total protein lysates were harvested from the ventricles of sham-operated rats treated with vehicle and aorta-banded rats treated with vehicle, carvedilol, metoprolol or terazosin. Phosphorylation of calcineurin, NFAT3 and GATA4 was determined by Western blotting using phosphorylation-specific antibodies (A). Equal protein loading was confirmed using total proteins and $\beta$-actin antibodies. The ratio of phosphorylated to total proteins is shown as the fold-increase relative to the control (B). ${ }^{\mathrm{a}} \mathrm{p}<0.05$ vs. sham group; ${ }^{\mathrm{b}} \mathrm{p}<0.05$ vs. vehicle group; $\mathrm{n}=10$ per group.

A

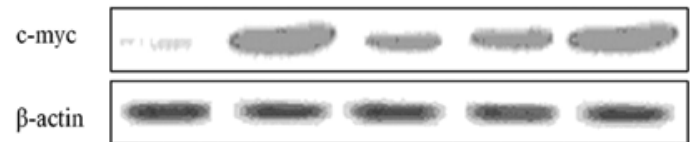

B

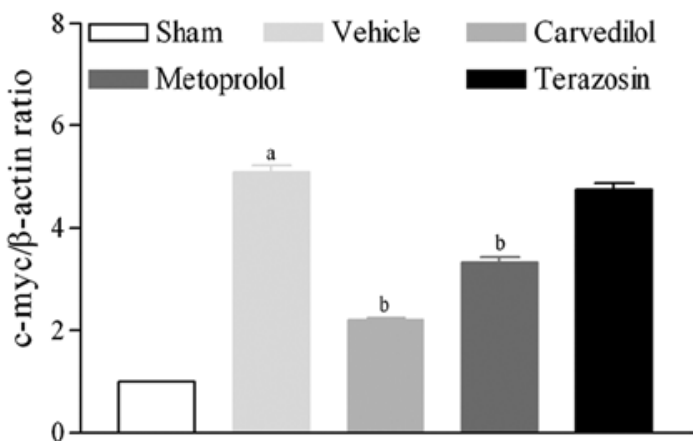

Figure 3. Protein expression of c-myc. Total protein lysates were harvested from the ventricles of sham-operated rats treated with vehicle and aorta-banded rats treated with vehicle, carvedilol, metoprolol or terazosin. The level of c-myc was determined by Western blotting (A). Equal protein loading was confirmed using $\beta$-actin antibody. The ratio of $c$-myc/ $\beta$-actin is shown in the bar graph (B). ${ }^{\mathrm{a}} \mathrm{p}<0.05$ vs. sham group; ${ }^{\mathrm{b}} \mathrm{p}<0.05$ vs. vehicle group; $\mathrm{n}=10$ per group. 
in the NFAT3 phosphorylation level $(\mathrm{p}<0.05)$ compared to the sham-operated rats (Fig. 2A and B). Notably, these changes were significantly attenuated by treatment with carvedilol or metoprolol (both $\mathrm{p}<0.05$ ). By contrast, the phosphorylation levels of calcineurin/NFAT3/GATA4 in terazosin-treated rats were similar to those in the vehicle-treated rats. Additionally, the total protein expression of calcineurin/NFAT3/GATA4 was unaffected by either aortic banding or adrenergic receptor blockade (Fig. 2A and B).

Expression of the early response gene c-myc. Little c-myc protein was expressed in the hearts of the sham-operated rats (Fig. 3A and B). However, c-myc was markedly up-regulated in the hypertrophic ventricles of pressure overloaded rats $(p<0.05)$. This increase was significantly suppressed by treatment with carvedilol or metoprolol (both $\mathrm{p}<0.05$ ). Conversely, treatment with terazosin had no effect on c-myc protein expression (Fig. 3A and B).

\section{Discussion}

There are two major findings in the present study. First, pressure-overload cardiac hypertrophy is characterized by a significant increase in calcineurin activity, which is associated with a concurrent reduction of NFAT3 phosphorylation and increased phosphorylation of GATA4. Second, adrenergic receptor blockade with carvedilol or metoprolol, but not terazosin, normalizes the calcineurin/NFAT3/GATA4 pathway in addition to attenuating pressure-overload cardiac hypertrophy. Of note, the beneficial effects of carvedilol on the regression of morphological remodeling and the normalization of the signaling pathway were superior to the actions of metoprolol.

A number of recent studies have investigated calcineurin activity in various animal models of cardiac hypertrophy $(1,16,18,19)$. Several studies demonstrated an increase in calcineurin activity in pressure-overload hypertrophy (18-21). However, a decrease in calcineurin protein expression in the hypertrophic heart has also been reported (22). These inconsistent results may be due to differences in the animal models used or in the severity of cardiac hypertrophy. The present study demonstrated that pressure overload significantly increased the phosphorylation level of calcineurin, but not its total protein expression. Although numerous studies have focused on the role of calcineurin, little attention has been paid to its direct downstream transcriptional effectors, including NFAT3 and GATA4. The present study revealed a marked decrease in phosphorylated NFAT3 expression and an increase in phosphorylated GATA4 expression in a pressure-overloaded animal model. These findings suggest that the calcineurin/NFAT3/GATA4 pathway plays a critical role in the development of pressure overload-induced cardiac hypertrophy.

Based on the protracted sympathoadrenal activation observed in heart failure, adrenergic receptor blockade has been accepted as a powerful tool for the management of this disease $(23,24)$. Although the adrenergic receptor blockers are widely used to prevent cardiac hypertrophy $(25,26)$, the underlying mechanisms of their effect remain to be elucidated. It has also been reported that sympathetic activation plays a critical role in the pressure-overload rat model of abdominal aortic constriction $(27,28)$. In this regard, adrenergic receptor blockade is likely to be an effective tool for the prevention of pressure overload-induced ventricular hypertrophy. This hypothesis was confirmed by the current study: both hemodynamics and histological changes were positively affected by treatment with carvedilol or metoprolol.

As previously mentioned, the exploration of novel drugs effective against the calcineurin/NFAT3/GATA4 pathway is warranted. In the present study, oral administration of the non-selective $\beta$ blocker/ $\alpha-1$ blocker carvedilol or the selective $\beta-1$ blocker metoprolol, but not the selective $\alpha-1$ blocker terazosin, significantly suppressed the calcineurin/NFAT3/ GATA4 pathway, suggesting that the $\beta$-adrenergic receptor but not the $\alpha$-adrenergic receptor is involved in the activation of this signaling pathway. These results are consistent with our hemodynamic and histological observations, which showed that the degree of ventricular hypertrophy and remodeling was improved by $\beta$-receptor blockers, but not $\alpha$-receptor blockers. Carvedilol was more efficacious than metoprolol in improving histological changes and normalizing molecular signals.

In conclusion, this study suggests that calcineurin is activated in pressure-overload hypertrophy. Activated calcineurin is likely to be responsible for numerous intracellular effects, including the dephosphorylation of NFAT3 and the phosphorylation of GATA4, resulting in fetal hypertrophic gene c-myc expression. The novel finding of this study is that adrenergic receptor blockade normalized the calcineurin/NFAT3/ GATA4 signaling pathway, in addition to inducing a regression of pressure-overload cardiac hypertrophy. The present findings may contribute to our understanding of the mechanisms behind and role of sympathetic activation in pressure overload-induced cardiac hypertrophy. More significantly, the identification of calcineurin/NFAT3/GATA4 as a pivotal molecular modulator of hypertrophy and remodeling makes it an attractive therapeutic target in hypertrophic heart disease.

\section{Acknowledgements}

We acknowledge Dr Dezhi $\mathrm{Mu}$ of the University of California-San Francisco for the supply of the primary antibodies. This work was supported by the Natural Science Foundation of China (No. 39970304).

\section{References}

1. Sakata Y, Masuyama T, Yamamoto K, Nishikawa $N$, Yamamoto H, Kondo H, Ono K, Otsu K, Kuzuya T, Miwa T, Takeda H, Miyamoto E and Hori M: Calcineurin inhibitor attenuates left ventricular hypertrophy, leading to prevention of heart failure in hypertensive rats. Circulation 102: 2269-2275, 2000.

2. Wagoner LE and Walsh RA: The cellular pathophysiology of progression to heart failure. Curr Opin Cardiol 11: 237-244, 1996.

3. Haq S, Choukroun G, Lim H, Tymitz KM, Del Monte F, Gwathmey J, Grazette L, Michael A, Hajjar R, Force T and Molkentin JD: Differential activation of signal transduction pathways in human hearts with hypertrophy versus advanced heart failure. Circulation 103: 670-677, 2001.

4. Molkentin JD, Lu JR, Antos CL, Markham B, Richardson J, Robbins J, Grant SR and Olson EN: A calcineurin-dependent transcriptional pathway for cardiac hypertrophy. Cell 93: 215-228, 1998.

5. Ritter O, Hack S, Schuh K, Rothlein N, Perrot A, Osterziel KJ, Schulte HD and Neyses L: Calcineurin in human heart hypertrophy. Circulation 105: 2265-2269, 2002. 
6. Zhang W: Old and new tools to dissect calcineurin's role in pressure-overload cardiac hypertrophy. Cardiovasc Res 53: 294-303, 2002.

7. Sussman MA, Lim HW, Gude N, Taigen T, Olson EN, Robbins J, Colbert MC, Gualberto A, Wieczorek DF and Molkentin JD Prevention of cardiac hypertrophy in mice by calcineurin inhibition. Science 281: 1690-1693, 1998.

8. Walsh RA: Calcineurin inhibition as therapy for cardiac hypertrophy and heart failure: requiescat in pace? Circ Res 84: 741-743, 1999.

9. Luo Z, Shyu KG, Gualberto A and Walsh K: Calcineurin inhibitors and cardiac hypertrophy. Nat Med 4: 1092-1093, 1998.

10. Force T, Rosenzweig A, Choukroun G and Hajjar R: Calcineurin inhibitors and cardiac hypertrophy. Lancet 353: 1290-1292, 1999.

11. Meguro T, Hong C, Asai K, Takagi G, McKinsey TA, Olson EN and Vatner SF: Cyclosporine attenuates pressure-overload hypertrophy in mice while enhancing susceptibility to decompensation and heart failure. Circ Res 84: 735-740, 1999.

12. Hojo M, Morimoto T, Maluccio M, Asano T, Morimoto $\mathrm{K}$, Lagman M, Shimbo $\mathrm{T}$ and Suthanthiran M: Cyclosporine induces cancer progression by a cell-autonomous mechanism. Nature 397: 530-534, 1999.

13. Palazzesi S, Musumeci M, Catalano L, Patrizio M, Stati T, Michienzi S, Di Certo MG, Mattei E, Vitelli L and Marano G: Pressure overload causes cardiac hypertrophy in beta1adrenergic and beta2-adrenergic receptor double knockout mice. J Hypertens 24: 563-571, 2006.

14. Balke CW and Shorofsky SR: Alterations in calcium handling in cardiac hypertrophy and heart failure. Cardiovasc Res 37 290-299, 1998.

15. Molkentin JD: Calcineurin and beyond: cardiac hypertrophic signaling. Circ Res 87: 731-738, 2000.

16. Zou Y, Hiroi Y, Uozumi H, Takimoto E, Toko H, Zhu W, Kudoh S, Mizukami M, Shimoyama M, Shibasaki F, Nagai R, Yazaki Y and Komuro I: Calcineurin plays a critical role in the development of pressure overload-induced cardiac hypertrophy. Circulation 104: 97-101, 2001.

17. Yang D, Ma S, Li D, Tang B and Yang Y: Angiotensin II receptor blockade improves matrix metalloproteinases/tissue inhibitor of matrix metalloproteinase-1 balance and restores fibronectin expression in rat infarcted myocardium. Biochem Biophys Res Commun 388: 606-611, 2009.

18. Shimoyama M, Hayashi D, Takimoto E, Zou Y, Oka T, Uozumi H, Kudoh S, Shibasaki F, Yazaki Y, Nagai R and Komuro I: Calcineurin plays a critical role in pressure overloadinduced cardiac hypertrophy. Circulation 100: 2449-2454, 1999.

19. Lim HW, De Windt LJ, Steinberg L, Taigen T, Witt SA, Kimball TR and Molkentin JD: Calcineurin expression, activation, and function in cardiac pressure-overload hypertrophy. Circulation 101: 2431-2437, 2000.
20. Eto Y, Yonekura K, Sonoda M, Arai N, Sata M, Sugiura S, Takenaka K, Gualberto A, Hixon ML, Wagner MW and Aoyagi T: Calcineurin is activated in rat hearts with physiological left ventricular hypertrophy induced by voluntary exercise training. Circulation 101: 2134-2137, 2000.

21. Hayashida W, Kihara Y, Yasaka A and Sasayama S: Cardiac calcineurin during transition from hypertrophy to heart failure in rats. Biochem Biophys Res Commun 273: 347-351, 2000.

22. Ding B, Price RL, Borg TK, Weinberg EO, Halloran PF and Lorell BH: Pressure overload induces severe hypertrophy in mice treated with cyclosporine, an inhibitor of calcineurin. Circ Res 84: 729-734, 1999.

23. Azevedo ER, Kubo T, Mak S, Al-Hesayen A, Schofield A, Allan R, Kelly S, Newton GE, Floras JS and Parker JD: Nonselective versus selective beta-adrenergic receptor blockade in congestive heart failure: differential effects on sympathetic activity. Circulation 104: 2194-2199, 2001.

24. Spinale FG, Johnson WS, Wang Y, Wang Z, Mukherjee R, Hebbar L and Jones BU: Direct effects of chronic beta-adrenergic receptor blockade on left ventricular and myocyte function in a model of tachycardia-induced congestive heart failure. J Card Fail 2: 311-318, 1996.

25. Asai T, Kushiro T, Fujita $H$ and Kanmatsuse K: Different effects on inhibition of cardiac hypertrophy in spontaneously hypertensive rats by monotherapy and combination therapy of adrenergic receptor antagonists and/or the angiotensin II type 1 receptor blocker under comparable blood pressure reduction. Hypertens Res 28: 79-87, 2005

26. Liao Y, Asakura M, Takashima S, Ogai A, Asano Y, Shintani Y, Minamino T, Asanuma H, Sanada S, Kim J, Kitamura S, Tomoike H, Hori M and Kitakaze M: Celiprolol, a vasodilatory beta-blocker, inhibits pressure overload-induced cardiac hypertrophy and prevents the transition to heart failure via nitric oxide-dependent mechanisms in mice. Circulation 110: 692-699, 2004.

27. Tamai J, Hori M, Kagiya T, Iwakura K, Iwai K, Kitabatake A, Watanabe Y, Yoshida H, Inoue M and Kamada T: Role of alpha 1-adrenoceptor activity in progression of cardiac hypertrophy in guinea pig hearts with pressure overload. Cardiovasc Res 23: 315-322, 1989.

28. Akers WS, Cross A, Speth R, Dwoskin LP and Cassis LA Renin-angiotensin system and sympathetic nervous system in cardiac pressure-overload hypertrophy. Am J Physiol Heart Circ Physiol 279: H2797-H2806, 2000. 